PROFESI (Profesional Islam): Media Publikasi Penelitian

2019; Volume 16; No 2.

Website: ejournal.stikespku.ac.id

\title{
Hubungan Komunikasi Terpeutik Perawat Dengan Kepuasan Pasien Terhadap Prosedur Tindakan Invasif
}

\author{
Wijayanti $^{1 *}$, Nabhani ${ }^{2}$, Shara Pratitys Damayanti ${ }^{3}$ \\ ${ }^{1,2}$ Dosen Prodi D III Keperawatan STIKES PKU Muhammadiyah Surakarta \\ ${ }^{3}$ Mahasiswa Program D III Keperawatan STIKES PKU Muhammadiyah Surakarta \\ *Email: wijayanti0603@stikespku.ac.id
}

\begin{abstract}
Kata Kunci
Komunikasi

Terapeutik

Perawat,

Kepuasan

Pasien
\end{abstract}

Abstrak

Komunikasi terapeutik dapat menjadi salah satu indikator dalam mengukur kepuasan pasien, apabila komunikasi terapeutik tidak dilakukan akan menyebabkan sulit terciptanya hubungan saling percaya antara klien dan perawat yang mempengaruhi kepuasan yang dirasakan oleh pasien. Studi pendahuluan yang dilakukan peneliti di Bangsal dewasa RSUD Surakarta didapatkan 2 pasien menyatakan puas, 3 pasien mengatakan kurang puas pada aspek komunikasi perawat dan perhatian pada saat memberikan tindakan invasif. Mengetahui hubungan komunikasi terapeutik perawat dengan kepuasan pasien terhadap prosedur tindakan invasif. Penelitian menggunakan korelasi dengan pendekatan cross sectional yang dilakukan di Bangsal dewasa RSUD Surakarta dengan teknik sampling purposive sampling 15 responden perawat dan 15 responden pasien dengan kuesioner. Analisa data yang digunakan spearmen rank pada signifikansi 5\%terdapat hubunganantara komunikasi terapeutik perawat dengan kepuasan pasien terhadap prosedur tindakan invasif yang memiliki keeratan hubungan yang kuat sebesar $78 \%$ dengan nilai $r=0,784$. Nilai $p$-value $=0,001$ sedangkan nilai rtabel=0,514 dan rhitung=0,784. Terdapat hubungan antara komunikasi terapeutik perawat dengan kepuasan pasien terhadap prosedur tindakan invasif dimana semakin baik komunikasi terapeutik yang dilakukan perawat maka kepuasan pasien juga semakin meningkat...

\section{The Correlation Between The Nurses' Therapeutic Communication and The Patients' Satisfaction with The Procedure of Invasive Action}

\begin{abstract}
Key Words: Abstract
Nurses'

Therapeutic

Communicati

on,

Therapeutic communication can be one of indicators in measuring the patients' satisfaction. If the therapeutic communication is not conducted, it can cause a difficulty in creating a relation which trust each other between clients and nurses which influence the sastisfaction felt by the patients. An introductory study conducted

Patients,

Satisfaction by the researcher in the adult ward of RSUD Surakarta (Regional Public Hospital of Surakarta) obtained results that there were 2 patients who felt satisfied, 3 patients felt less satisfied on the nurses' communication aspect and attention when giving an invasive action. To know the correlation between the nurses' therapeutic communication and the patients' satisfaction with the procedure of invasive action.. The research used correlation with a cross sectional approach which was conducted in the adult ward of RSUD Surakarta using the sampling of purposive sampling as many as 15 respondents of nurses and 15 respondents of patients and use a quesionareThe data analysis used spearmen rank in the significance level of 5\%. There is a correlation between the nurses' therapeutic communication and the patients' satisfaction with the procedure of invasive action which has a very strong correlation as much as $78 \%$ with the score of $r=0,784$. The score of $p$-value=0,001, meanwhile, the score of rtable $=0,514$ and rcount $=0,784$. there is a correlation between the nurses' therapeutic communication and the patients'satisfaction with the procedure of invasive action in which the better the therapeutic communication conducted by the nurses, the higher the patients'satisfaction.
\end{abstract}




\section{PENDAHULUAN}

Pelayanan harus dapat memberikan kepuasan pada pasien, tidak semata-mata hanya kesembuhan belaka. Salah satu aspek kepuasan pasien yaitu hubungan pasien dengan petugas rumah sakit salah satunya adalah komunikasi antar perawat dan pasien. Komunikasi terapeutik merupakan komunikasi yang memiliki tujuan dan direncanakan dengan sengaja serta berfokus pada kesembuahan pasien yang dilakukan oleh perawat ataupun tenaga kesehatan lain (Machfoedz, 2009). Terdapat empat fase dalam komunikasi terapeutik yaitu fase pra-interaksi, fase orientasi, fase kerja, dan terminasi. Sanders (2009) menjelaskan ketidakpuasan pasien ketidakcukupan informs yang diberikan oleh perawat kepada pasien. Hasil survey yang dilakukan oleh Rush University Medical Center (2013) bahwa perawat dianggap berkomunikasi dengan baik apabila melakukan komunikasi dengan intensitas sering, dan menjelaskan sesuatu dengan jelas, mendengarkan pasien dengan sungguh-sungguh, dan memperlakukan pasien dengan sopan dan hormat

Setiap fase tersebut harus dilakukan oleh perawat untuk menciptakan komunikasi terapeutik yang baik dan memberikan kepuasan pelayanan kepada klien. Menurut (Suryani, 2006) jika komunikasi terapeutik tersebut tidak dilakukan akan menyebabkan sulit terciptanya hubungan saling percaya antara klien dan perawat. Apabila hubungan saling percaya tidak terbentuk akan berakibat pada tingkat kepuasan yang dirasakan oleh pasien terhadap pelayanan yang diberikan. Hal ini yang membuat komunikasi terapeutik sangat diperlukan dan dapat menjadi salah satu indikator dalam pengukuran kepuasan pasien.

Keberhasilan asuhan dan komunikasi yang baik tentunya akan membuat pasien merasa puas terhadap pelayanan yang didapatkannya. Kepuasan pasien merupakan nilai subjektif terhadap kualitas pelayanan yang diberikan (Sabarguna \& Rubaya, 2011). Aspek kepuasan pasien meliputi, responsiveness (ketanggapan), reliability (keandalan), emphaty (empati), assurance (jaminan), tangibles (bukti langsung) (Rangkuti, 2006). Penelitian Sari (2013) mengatakan bahwa kepu- tusan berobat berpengaruh terhadap kepuasan pasien.

Studi pendahuluan pada 1 November 2016 di RSUD Surakarta, dengan mengobservasi enam perawat, pada fase pra-interaksi semua perawat melakukan komunikasi terapeutik dengan baik, fase orientasi $83,3 \%$ perawat tidak pernah memperkenalkan dirinya hanya mengidentifikasi pasien saja dan tidak menjelaskan prosedur dan tujuan tindakan. Pada fase kerja 50\% perawat hanya berfokus dengan tindakan saja dan kadangkadang menanggapi respon pasien, dalam fase terminasi $83,3 \%$ perawat tidak melakukan komunikasi terapeutik dengan pasien. Sebanyak 83,3\% perawat kurang melakukan komunikasi terapeutik dengan baik pada fase orientasi, fase kerja, dan fase terminasi. Sedangkan wawancara kepada lima pasien rawat inap di bangsal dewasa RSUD Surakarta, dua pasien mengatakan puas terhadap pelayanan yang diberikan oleh perawat, tiga pasien mengatakan kurang puas pada aspek komunikasi perawat dan perhatian pada saat memberikan tindakan invasif. Fatriansari (2012) menyatakan bahwa terdapat hubungan yang bermakna antara komunikasi terapeutik perawat anak dengan tingkat kepuasan keluarga. Hal serup juga dijelaskan oleh Mappa (2009) hubungan positif antara persepsi pasien tentang komunikasi perawat dengan tingkat kepuasan pasien terhadap komunikasi.

Komunikasi adalah proses yang penting dalam berhubungan terutama dalam pelayanan keperawatan. Keliat, Akemat, Helena, \& Nurhaeni (2015) menjelasakan komunikasi adalah komponen utama dalam berhubungan antar manusia yang dilakukan oleh dua orang atau lebih yang terdiri dari pertukaran informasi, perasaan, pikiran dan perilaku. Penyampaian komunikasi ini menurut Stuart (2013) dapat melalui komunikasi verbal dan non verbal. Keliat (2015) menjelaskan tahapan komunikasi terapeutik yaitu tahap prainteraksi, tahap orientasi, tahap kerja, dan tahap terminasi.

Tujuan penelitian ini adalah menganalisis hubungan komunikasi terapeutik perawat dengan kepuasan pasien terhadap prosedur tindakan invasif". 
PROFESI (Profesional Islam): Media Publikasi Penelitian 2019; Volume 16; No 2.

Website: ejournal.stikespku.ac.id

\section{METODE PENELITIAN}

Penelitian ini merupakan penelitian cross sectional yang melibatkan 15 orang pasien dan 15 orang perawat yang diambil secara purposive sampling bangsal dewasa RSUD Surakarta. Kriteria inklusi perawat adalah perawat yang bersedia menjadi responden sedangkan kriteria inklusi pasien: pasien yang mendapatkan prosedur injeksi IM, IV, SC, IC dan pengambilan darah vena secara langsung ke tubuh pasien, pasien yang mendapatkan tindakan pemasangan kateter ataupun NGT, pasien yang bersedia menjadi responden. Responden yang dijadikan responden diminta mengisi informed consent serta menjaga kerahasian data yang diberikan oleh responden. Pengambilan data penelitian menggunakan kuesioner dan disajikan dalam bentuk distribusi frekuensi serta dianalisis menggunakan uji Spearmen Rank.

\section{HASIL DAN PEMBAHASAN}

Tabel 1. Distribusi Frekuensi Berdasar Umur

\begin{tabular}{ccccc}
\hline Umur & Perawat & $\begin{array}{c}\text { Persen- } \\
\text { tase }\end{array}$ & Pasien & $\begin{array}{c}\text { Persen- } \\
\text { tase }\end{array}$ \\
\hline 18-40 tahun & 15 & $100 \%$ & 6 & $40,1 \%$ \\
40-60 tahun & 0 & $0 \%$ & 8 & $53,3 \%$ \\
$>60$ tahun & 0 & $0 \%$ & 1 & $6,7 \%$ \\
Total & 15 & $100 \%$ & 15 & $100 \%$ \\
\hline
\end{tabular}

Sumber: Data Primer (2017)

Responden masuk dalam katagori dewasa dini 18-40 tahun ada 15 orang (100\%). Semakin dewasa umur seseorang maka pemikiran dan emosi seseorang akan semakin matang sehingga seiring dengan bertambahnya usia kualitas komunikasi akan semakin baik karena mereka yang memiliki emosi yang stabil akan lebih bisa memahami orang lain. Usia memiliki hubungan dengan keadaan emosi yang merupakan perasaan subyektif terhadap suatu kejadian. Emosi seperti marah, sedih, senang akan dapat mempengaruhi perawat dalam berkomunikasi dengan orang lain (Rahil, 2012).

Responden berdasarkan umur pasien mayoritas masuk katagori dewasa madya sebanyak 8 orang $(53,3 \%)$.Semakin dewasa seseorang maka semakin banyak pengalaman hidup yang dilalui, hal ini tentunya akan membuat mereka lebih bisa menilai dengan rasional dan kritis tentang komunikasi yang dilakukan perawat dengan kepuasan mereka terhadap pelayanan perawat. Sejalan dengan pernyataan Siagian dalam Hajarudin (2014) bahwa seseorang akan semakin mampu mengambil keputusan, lebih bijaksana, lebih mampu berfikir rasional, lebih dapat mengendalikan emosi dengan bertambahnya usia. Penelitian Dzomenku (2012), Otani (2011), dan Batbaatar dkk (2017) menjelaskan bahwa umur akan berpengaruh terhadap kepusan seseorang.

Tabel 2. Distribusi Frekuensi

Berdasar Jenis Kelamin

\begin{tabular}{ccccc}
\hline $\begin{array}{c}\text { Jenis } \\
\text { kelamin }\end{array}$ & Perawat & Persentase & Pasien & Persentase \\
\hline Laki-laki & 5 & $33,3 \%$ & 7 & $46,7 \%$ \\
Perempuan & 10 & $66,7 \%$ & 8 & $53,3 \%$ \\
$\quad$ Total & 15 & $100 \%$ & 15 & $100 \%$ \\
\hline
\end{tabular}

Sumber: Data Primer (2017)

Responden perawat mayoritas berjenis kelamin perempuan ada 10 orang $(66,7 \%)$, sisanya ada 5 orang $(33,3 \%)$ berjenis kelamin laki-laki. Perempuan cenderung menggunakan perasaannya dalam perpikir, mereka akan lebih peka terhadap keluhan pasien sehingga perempuan lebih bisa menafsirkan pesan yang disampaikan oleh pasien baik pesan secara verbal maupun non verbal, sehingga perempuan lebih baik dalam berkomunikasi. Jenis kelamin dapat mempengaruhi seseorang pada saat berinteraksi. Gaya komunikasi yang berbeda tersebut dapat mempengaruhi seseorang dalam menafsirkan pesan yang diterimanya (Potter dalam Hajarudin, 2014).

Responden pasien berdasar jenis kelamin, mayoritas berjenis kelamin perempuan ada 8 orang $(53,3 \%)$. Jenis kelamin memiliki pengaruh pada pandangan terhadap jasa yang diberikan. Perempuan lebih banyak melihat penampilan secara detail, sementara laki-laki cenderung tidak peduli dibandingkan perempuan, karena itu mereka lebih dianggap fleksible dibandingkan perempuan (Gunarsa dalam Oroh, dkk, 2014). Responden perempuan seharusnya akan lebih bisa menilai kepuasannya terhadap pelayanan 
PROFESI (Profesional Islam): Media Publikasi Penelitian 2019; Volume 16; No 2.

Website: ejournal.stikespku.ac.id

yang diperolehnya secara maksimal. Hasil penelitian Oroh, dkk (2014) menyatakan adanya hubungan yang bermakna antara jenis kelamin dengan tingkat kepuasan pasien rawat inap. Hal serupa disampaikan oleh Batbaatar dkk (2017) dan Yasmin (2002). Berbeda dengan Senarath (2013) bahwa kepuasan lebih banyak dirasakan oleh laki-laki.

Tabel 3. Distribusi Frekuensi Berdasar Pendidikan

\begin{tabular}{ccccc}
\hline Pendidikan & Perawat & Persentase & Pasien & Persentase \\
\hline SD & 0 & $0 \%$ & 3 & $20 \%$ \\
SMP & 0 & $0 \%$ & 5 & $33,3 \%$ \\
SMA & 0 & $0 \%$ & 7 & $46,6 \%$ \\
Diploma III & 15 & $100 \%$ & 0 & $0 \%$ \\
S1 & 0 & $0 \%$ & 0 & $0 \%$ \\
Total & 15 & $100 \%$ & 15 & $100 \%$ \\
\hline
\end{tabular}

Sumber: Data Primer (2017)

Keseluruhan responden perawat 15 orang (100\%) berpendidikan diploma III. Pendidikan berarti bimbingan yang diberikan seseorang terhadap tahap perkembangan orang lain menuju ke arah cita-cita tertentu. Mengidentifikasi pengetahuan, persepsi dan pemahaman pasien, dapat membantu perawat mempersiapkan kondisi emosional pasien. Hal ini dapat disimpulkan bahwa pendidikan yang tinggi dapat mempengaruhi keberhasilan dalam berkomunikasi (Andansari, 2014).

Mayoritas pasien berpendidikan SMA yaitu 7 orang (46,6\%). Rismiyati (2015) menyatakan, responden dengan tingkat pendidikan lebih rendah akan merasa lebih cepat puas. Tingkat pengetahuan seseorang akan cenderung membantunya membentuk suatu pengetahuan, sikap, dan perilakunya terhadap sesuatu. Sehingga seseorang dengan pendidikan yang lebih tinggi semestinya akan lebih kritis dalam menentukan apakah pelayanan yang diperolehnya dapat memberikan rasa puas atau tidak.

Tabel 4. Distribusi Frekuensi Berdasar Pekerjaan Responden Pasien

\begin{tabular}{ccc}
\hline Pekerjaan & Frekpasien & Persentase \\
\hline Bekerja & 11 & $73,3 \%$ \\
Tidak bekerja & 4 & $26,7 \%$ \\
Total & 15 & $100 \%$ \\
\hline
\end{tabular}

Sumber: Data Primer (2017)

Mayoritas responden masuk dalam katagori bekerja 11 orang $(73,3 \%)$. Mereka yang bekerja akan lebih mudah bergaul dengan lingkungan. Mayoritas responden dalam katagori bekerja, hal ini berarti pasien memiliki tambahan pengalaman secara langsung atau tidak langsung berkaitan dengan kualitas pelayanan selama menjalani perawatan, sehingga mereka dapat menilai kualitas pelayanan yang diterimanya dan dapat memberikan gambaran tentang kepuasan yang mereka rasakan. Iqbal dalam Andriyani (2015) menyatakan, lingkungan pekerjaan dapat menjadikan seseorang memperoleh pengalaman dan pengetahuan baik secara langsung maupun tidak langsung.

Tabel 5. Distribusi Frekuensi Berdasar Lama Masa Kerja Perawat

\begin{tabular}{ccc}
\hline Masa Kerja & Frekuensi & Persentase \\
\hline$\leq 1$ tahun & 0 & $0 \%$ \\
$>1$ tahun & 15 & $100 \%$ \\
Total & 15 & $100 \%$
\end{tabular}

Sumber: Data Primer (2017)

Lama masa kerja perawat mayoritas responden ada 15 orang perawat (100\%) memiliki masa kerja lebih dari 1 tahun.Lama bekerja merupakan kurun waktu atau lama waktu yang telah dilalui perawat sejak mulai bekerja di bangsal dewasa RSUD Surakarta sampai dengan dilakukannya penelitian saat ini. Semakin lama masa kerja perawat akan menambah pengalaman mereka baik pengalaman berkomunikasi ataupun pengalaman melakukan tindakan keperawata. Hal tersebut didukukung oleh pendapat Notoatmodjo dalam Sari (2014) yang menjelaskan bahwa pengetahuan seseorang dapat dipengaruhi oleh beberapa faktor diantaranya adalah pengalaman kerja. 
PROFESI (Profesional Islam): Media Publikasi Penelitian 2019; Volume 16; No 2.

Website: ejournal.stikespku.ac.id

Tabel 6. Distribusi Frekuensi Berdasar Lama Rawat Inap Pasien

\begin{tabular}{ccc}
\hline Lama rawat inap & Frekuensi & Persentase \\
\hline$\leq 3$ hari & 0 & $0 \%$ \\
$>3$ hari & 15 & $100 \%$ \\
Total & 15 & $100 \%$ \\
\hline
\end{tabular}

Sumber: Data Primer (2017)

Semua responden (100\%) menjalani rawat inap lebih dari tiga hari. Lama rawat inap berpengaruh terhadap tingkat kepuasan yang dirasakan oleh pasien. Semakin lama seseorang menjalani rawaat inap, mereka akan lebih mengenali dan terbiasa dengan lingkungannya sehingga ia akan bisa menilai apakah pelayanan yang diperolehnya memberika rasa puas atau tidak. Pernyataan ini didukung oleh hasil penelitian Oroh, dkk (2014) yang menyatakan bahwa ada hubungan yang bermakna antara lama perawatan dengan tingkat kepuasan pasien rawat inap.

Tabel 7. Distribusi Frekuensi Berdasar Komunikasi Terapeutik Perawat

\begin{tabular}{ccc}
\hline $\begin{array}{c}\text { Komunikasi } \\
\text { Terapeutik }\end{array}$ & Frekuensi & Persentase \\
\hline Baik & 13 & $86,7 \%$ \\
Sedang & 2 & $13,3 \%$ \\
Kurang baik & 0 & $0 \%$ \\
Total & 15 & $100 \%$ \\
\hline
\end{tabular}

Sumber: Data Primer (2017)

Komunikasi terapeutik perawat mayoritas berada pada katagori baik yaitu 13 orang $(86,7 \%)$. Komunikasi terapeutik adalah pengalaman interaktif antara perawat dan pasien dalam komunikasi yang bertujuan untuk menyelesaikan masalah yang sedang dihadapi pasien (Mafchfoedz, 2009). Lebih jauh, komunikasi sangat penting karena dapat mempengaruhi tingkat kepuasan pasien terhadap pelayanan kesehatan yang diberikan. Penyebab sumber ketidakpuasan pasien sering disebabkan karena jeleknya komunikasi yang terjalin dengan pasien (Robby dalam Hajarudin, 2014).

Komunikasi terepeutik yang baik dari perawat akan berpengaruh terhadap peningkatan kepuasan pasien. Hal ini didukung oleh penelitian
Rismiyati (2015) dengan hasil penelitian menunjukkan ada 35 orang $(59,32 \%)$ telah melakukan komunikasi terapeutik dengan baik. Hal tersebut membuktikan bahwa komunikasi terapeutik yang baik akan menciptakan kepuasan yang baik pula.

Tabel 8. Distribusi Frekuensi Berdasar Kepuasan Pasien

\begin{tabular}{ccc}
\hline Kepuasan Pasien & Frekuensi & Prosentase \\
\hline Puas & 12 & $80 \%$ \\
Sedang & 3 & $20 \%$ \\
Kurang puas & 0 & $0 \%$ \\
Total & 15 & $100 \%$ \\
\hline
\end{tabular}

Sumber: Data Primer (2017)

Kepuasan pasien mayoritas masuk dalam katagori puas ada 13 orang (80\%), tingginya tingkat kepuasan pasien menunjukkan komunikasi terapeutik yang dilakukan perawat juga baik. Penelitian ini sejalan dengan penelitian Oroh, dkk (2014) dalam penelitiannya dari 100 responden ada 73 orang $(73 \%)$ menyatakan puas dengan pelayanan keperawatan. Kepuasan pasien merupakan tingkat perasaan pasien yang timbul sebagai akibat dari kinerja pelayanan kesehatan yang diperolehnya setelah pasien membandingkan dengan yang diharapkannya (Pohan, 2007).

Tingginya prosentase responden yang menyatakan puas terhadap prosedur tindakan invasif yang dilakukan oleh perawat dalam penelitian ini karena komunikasi terapeutik yang baik yang dilakukan oleh perawat. Penelitian Hajarudin (2014) diperoleh hasil dari 30 responden ada 24 atau $80 \%$ responden menyatakan puas dan 6 atau 20\% menyatakan kurang puas.

Tabel 9. Uji Normalitas Data

\begin{tabular}{ccc}
\hline Variabel & Sig. & Keterangan \\
\hline $\begin{array}{c}\text { Komunikasi } \\
\text { terapeutik } \\
\text { Kepuasan pasien }\end{array}$ & 0,080 & Normal \\
& 0,046 & Tidak normal
\end{tabular}

Sumber: Data Primer (2017)

Uji normalitas data menggunakan Shapiro Wilk, variabel komunikasi terapeutik perawat nilai $\operatorname{sig}=0,080($ sig $>0,05)$ sehingga berdistribusi normal. Sedangkan variabel kepuasan pasien 
PROFESI (Profesional Islam): Media Publikasi Penelitian 2019; Volume 16; No 2. Website: ejournal.stikespku.ac.id

memiliki nilai $\operatorname{sig}=0,046(\operatorname{sig}<0,05)$ berdistribusi tidak normal. Selanjutnya karena penelitian ini merupakan penelitian korelasi dan data berbentuk data ordinal maka uji statistik yang digunakan adalah spearmen rank.

Tabel 10. Distribusi Silang

\begin{tabular}{|c|c|c|c|c|c|c|}
\hline \multirow{2}{*}{ Variabel } & & \multicolumn{2}{|c|}{ Kepuasan } & \multirow{2}{*}{$\begin{array}{c}r \\
\text { tabel }\end{array}$} & \multirow{2}{*}{$\mathbf{r}_{\text {hitung }}$} & \multirow{2}{*}{$\begin{array}{c}p- \\
\text { value }\end{array}$} \\
\hline & & Puas & Sedang & & & \\
\hline \multirow{2}{*}{ Komunikasi } & Baik & $\begin{array}{c}12 \\
(80 \%)\end{array}$ & $\begin{array}{c}1 \\
(6,6 \%)\end{array}$ & \multirow[t]{3}{*}{0,514} & \multirow[t]{3}{*}{0,784} & \multirow[t]{3}{*}{0,001} \\
\hline & Sedang & 0 & $\begin{array}{c}2 \\
(13,3 \%)\end{array}$ & & & \\
\hline Total & & $\begin{array}{c}12 \\
(80 \%)\end{array}$ & $\begin{array}{c}3 \\
(19,3 \%)\end{array}$ & & & \\
\hline
\end{tabular}

Sumber: Data Primer (2017)

Nilai $p$-value $=0,001$ dilihat dari nilai $r_{\text {tabel }}=0,514$ dan $r_{\text {hitung }}=0,784$ sehingg $r_{\text {hitung }}>r_{\text {tabel }}$ $(0,784>0,514)$ artinya hipotesis yang berbunyi ada hubungan antara komunikasi terapeutik perawat dengan kepuasan pasien terhadap prosedur tindakan invasif diterima, yang memiliki keeratan hubungan yang kuat sebesar 78\% ditunjukkan dengan nilai $\mathrm{r}=0,784$ yang berada pada interval 0,60-0,799. Semakin baik komunikasi terapeutik maka kepuasan pasien akan semakin meningkat. Semakin sering perawat memberikan komunikasi terapeutik maka komunikasi antara pasien dan perawat akan semakin sering terjadi, dan kualitas asuhan keperawatan juga semakin tinggi karena adanya rasa percaya pasien yang meningkatkan kepuasan pasien (Ningsih, 2015).

Pelaksanaan komunikasi terapeutik yang baik dapat meningkatkan kepuasan pelayanan keperawatan yang dirasakan oleh pasien (Wijono dalam Hajarudin, 2014). Hasil dari penelitian ini sesuai dengan hasil penelitian Ariasti (2016), bahwa terdapat hubungan antara komunikasi terapeutik perawat dengan tingkat kepuasan pasien. Irawan (2015) menujukkan bahwa terdapat hubungan antara komunikasi terapeutik perawat dengan kepuasan pasien.

Komunikasi menjadi landasan dalam berinteraksi dengan pasien. Kompetensi perawat dalam berinteraksi dengan pasien menjadikan pasien merasa puas terhadap layanan yang diberi- kan. Klisiari \& Gaki (2012) menjelaskan bahwa pelayanan yang berkualitas ditentukan oleh komunikasi yang diberikan. Melalui komu-nikasi kebutuhan pasien akan tergali (Wiyati dalam Hajarudin, 2014).

\section{SIMPULAN}

Penelitian ini dapat disimpulkan bahwa, ada hubungan antara komunikasi terapeutik perawat dengan kepuasan pasien terhadap prosedur tindakan invasif. Mayoritas komunikasi terapeutik perawat baik yaitu 13 orang $(86,7 \%)$, kepuasan pasien terhadap prosedur tindakan invasif katagori puas yaitu 12 orang (80\%).

Adapun saran yang ingin peneliti sampaikan bagi profesi perawat diharapkan mampu melakukan komunikasi terapeutik dengan baik pada setiap fase komunikasi terapeutik. Bagi peneliti selanjutnya, diharapkan melakukan analisis komunikasi pada setiap tahap komunikasi dengan menggunakan metode observasi dalam menilai komunikasi perawat.

\section{REFERENSI}

Andansari, Andansari, O. (2014). Efektifitas Komunikasi Terapeutik Interpersonal Perawat Terhadap Tingkat Kecemasan Pasien Pre Operasi Fraktur di RSUD Dr. Moewardi. Surakarta: STIKES PKU Muhammadiyah Surakarta.

Andriyani, I. (2015). Hubungan Kualitas Pelayanan dalam Lima Dimensi Pelayanan dengan Kepuasan Pasien di Rawat Inap Puskesmas Bakti Kabupaten Sukoharjo. Diakses pada tanggal 15 Maret 2017,

Batbaatar, E., Dorjdagva, J., Luvsannyam, A., Savino, M. M., \& Amenta, P. (2017). Determinants of patient satisfaction: A systematic review. Perspectives in Public Health, 137(2), 89-101. doi:http://eresources.perpusnas.go.id:2136/10.1177/ 1757913916634136

Dzomeku, V. M; Atinga, Tuluku, Mantey. (2013). In Patient Satisfaction With Nursing care. International of Research JournalIn Medical and Health sciences. 
PROFESI (Profesional Islam): Media Publikasi Penelitian

2019; Volume 16; No 2.

Website: ejournal.stikespku.ac.id

Fatriansari. (2012). Hubungan komunikasi terapeutik perawat anak dan tingkat kepuasan keluarga yang anaknya menjalani hospitalisasi di RSUD AL Ihsan. Tesis. Propinsi Jabar.

Hajarudin. (2014). Hubungan Antara Komunikasi Terapeutik Perawat Dengan Tingkat Kepuasan Pasien Di Puskesmas Pleret Bantul Yogyakarta. Diakses pada tanggal 10 Maret 2017, <http://thesis.umy.ac.id/ datapublik/t34289.pdf $>$

Irawan, A.G. (2015). Hubungan Antara Komunikasi Terapeutik Perawat dengan Kepuasan Pasien Terhadap Pelayanan Kesehatan di Irna Rumah Sakit Muhammadiyah Palembang. Diakses pada tanggal 14 Oktober 2016 <http://sn.fdi.or.id/wpcontent/uploads/2015/11/Kesehatan-2Irawan20 7219.pdf.>

Keliat, B. A., Akemat, Helena, N., \& Nurhaeni, H. (2015). Keperawatan Kesehatan Jiwa Komunitas. Jakarta: EGC.

Klisiari, A., \& Gaki, A. (2012). The Concept of Communication Between Nurse and Patient in the Catheterization Laboratory. Hospital Chronicles. 7(1): 26-30. Retrieved from http://search.proquest.com/ docview/1689877528?accountid.

Mappa. (2009). Hubungan persepsi pasien tentang komunikasi perawat denaga kepuasan pasien terhadap komunikasi di RSUP Dr. Soeraji. Klaten

Oroh, M.E, dkk. (2014). Faktor-Faktor yang Berhubungan dengan Tingkat Kepuasan Pasien Rawat Inap Terhadap Pelayanan Keperawatan di Ruang Interna RSUD Noongan. Jurnal Keperawatan. 2 (2). Diakses pada tanggal 15 Maret 2017, $<$ http://ejournal.unsrat.ac.id/index.php/jk $\mathrm{p} /$ article/view/ 5220/ 4734>

Otani K, Herrmann PA, Kurz RS. (2011). Improving patient satisfaction in hospital care settings. Health Serv Manage Res 2011 Nov;24(4):163-169.

Pohan, I.S. (2007). Jaminan Mutu Layanan Kesehatan: Dasar-Dasar Pengertian dan
Penerapan. Jakarta: Buku Kedokteran EGC. Diakses pada tanggal 3 Oktober 2016.

$<$ https://books.google.co.id/books?isbn= 9794487279 >

Pohan, S., I. (2007). Jaminan Mutu Layanan Kesehatan: Dasar-dasar Pengertian dan Penerapan. Jakarta: EGC.

Rahil, N. H. (2012). Hubungan Komunikasi Terapeutik Perawat dalam Memberikan Obat dengan Tingkat Kepuasan Pasien dalam Pemberian Obat di Irna RSUD Sleman Yogyakarta. Diakses pada tanggal 21 September 2016, <http://journal. respati.ac.id/index.php/ilmukeperawatan/ issue/download/38/4>

Rangkuti, F. (2006). Measuring Customer Satisfaction Gaining Customer Relatonship Strategy Teknik Mengukur dan Strategi Meningkatkan Kepuasan Pelanggan. Jakarta: PT Gramedia Pustaka Utama. Diakses pada 3 Oktober 2016.

Rismiyati, T.C.M. (2015). Hubungan Komunikasi Terapeutk Perawat dengan Kepuasan Pelayanan Pasien Rawat Inap di Rumah Sakit Brayat Minulya Surakarta. Diakses pada 9 Maret 2017

Rush University Medical Center. (2013). Survey Hospital custumer of health pronder and system.

Sabarguna, B.S dan Rubaya, A.K. (2011). Sanitasi Lingkungan dan Bangunan Pendukung Kepuasan Pasien Rumah Sakit. Jakarta: Salemba Medika.

Sari, P. C. P. (2013). Faktor-Faktor yang Mempengaruhi Keputusan Berobat Serta Dampaknya Terhadap Kepuasan Pasien Skripsi. Semarang: Universitas Diponegoro Semarang. Diakses pada tanggal 26 Oktober 2016, <http://eprints.undip. ac.id/39566/ >

Sari, R. Y. (2014). Pengaruh Sosialisasi SOP $A P D$ dengan Perilaku Perawat dalam Peng-gunaan APD (Handscoon, Masker, Gown) Di Rsud Dr. H. Soewondo. Semarang: STIKES Telogorejo Semarang. Diakses pada tanggal 01 April 
PROFESI (Profesional Islam): Media Publikasi Penelitian 2019; Volume 16; No 2.

Website: ejournal.stikespku.ac.id

2017, < http://e-journal/index.php/ilmu keperawatan/article/view/280>

Senarath U, Gunawardena NS, Sebastiampillai B, Senanayake A, Lekamge S, Seneviratna A et al. (2013). Patient satisfaction with nursing care and related hospital services at the National Hospital of Sri Lanka. Leadership in Health Service. 26: 63-77.
Stuart, G. W., \& Sundeen S., J. (2013). Mental health nursing: Principle and practice. Mosby.

Suryani. (2006). Komunikasi Terapeutik: Teori dan Praktik. Jakarta: EGC. 